\title{
CRYSTALLITE SIZE AND MICROSTRAIN EVOLUTION IN LOW-TEMPERATURE ANNEALED TITANIUM
}

\author{
Tomas HORAZDOVSKY, Jan DRAHOKOUPIL, Jakub JINDRA, Petr VLCAK \\ Faculty of Mechanical Engineering, Czech Technical University in Prague, Czech Republic, EU
}

https://doi.org/10.37904/nanocon.2019.8706

\begin{abstract}
An in situ investigation has been carried out by X-ray diffraction of the evolution of the crystallite size and the microstrain of low-temperature annealed commercially pure titanium grade 2 in the state after machining and polishing. Annealing was performed in vacuum at a temperature of 300,400 and $500{ }^{\circ} \mathrm{C}$, with various dwell times. The results presented here demonstrate that annealing temperatures lead to a significant reduction in microstrain and enhanced crystallite growth. The effect of the dwell time is more pronounced at temperatures above $400{ }^{\circ} \mathrm{C}$. The dwell time at a temperature of $300{ }^{\circ} \mathrm{C}$ affects the crystallite growth but produces no microstrain relaxation. The presented results can be very useful for optimizing the working cycle and cooling during surface modification of titanium or exposed machines parts in order to improve the stability of the microstructure and extend the lifetime of components.
\end{abstract}

Keywords: Titanium, Annealing, Crystallite, Microstrain, X-ray diffraction

\section{INTRODUCTION}

Heat treatment procedures in combination with metalworking methods are used in designing the microstructure, the chemical properties and the mechanical properties of titanium materials. Aging/precipitation hardening of titanium materials and annealing treatments to increase ductility and remove stress are widely used at temperatures in the range from 530 to $840{ }^{\circ} \mathrm{C}$ [1-3]. Recrystallization of commercially pure titanium (CP Ti) was observed to take place at temperatures above $400^{\circ} \mathrm{C}$ [4]. Ultrafine-grain (UFG) titanium structures with relatively large stored energy were found to be sensitive to modest temperatures. However, no detectable softening was observed at temperatures below $400{ }^{\circ} \mathrm{C}[4,5]$. The annealing time affects the level and the completeness of the structural change. Liu et al. [6] recently studied the effect of annealing time on the grain coarsening and hardness of $\mathrm{CP} \mathrm{Ti}$ after annealing at $550{ }^{\circ} \mathrm{C}$. Low-angle grain boundaries were found to decrease gradually with increasing dwell of annealing. Rapid disappearance of twins was observed. A fully recrystallized structure was reached after 60 minutes. However, the evolution of the internal stress and its effect on mechanical properties has been not investigated. Sotniczuk et al. [7] reported on the effect of moderate temperatures on microstructural changes in titanium hydrostatically extruded into nanocrystalline form. Low temperature annealing at $250{ }^{\circ} \mathrm{C}$ led to an increase in hardness. Rearrangement of the grain boundary structure (better defined boundaries and an increasing fraction of high-angle grain boundaries) was suggested to be responsible for the increase in hardness.

Low performance in sliding and wear are the main reasons for modifying titanium surfaces [8]. Many concepts of surface modifications, e.g. low-friction coating deposition, nitriding and oxidizing, are under intensive research [9-11]. Insufficient tribomechanical properties of titanium materials lead to excessive friction and an increase in the operating temperature of moving parts. Fluctuations in operating temperatures up to $600^{\circ} \mathrm{C}$ can be reched in highly-stressed components of rotary and stationary parts (e.g. compressors blades, turbine discs of jet engines and housing parts of fans) $[3,12]$. In addition, the elevated processing temperature of promising methods for surface modification of titanium materials (e.g. plasma nitriding, plasma-based ion implantation, ion implantation and magnetron sputtering) can affect the microstructure and the application properties. The 
effect of moderate temperatures on microstructural changes in titanium materials therefore need to be investigated in greater detail.

In this letter, we report on the effect of moderate temperatures and the time of annealing on crystallite size and microstrain. The non-destructive X-ray diffraction method was used for precise microstructural measurements. The results presented here can be very useful for optimizing the working cycle and cooling during the surface modification of titanium or exposed machine parts in order to improve the stability of the microstructure and extend the lifetime of components.

\section{EXPERIMENTAL}

The material used in this study was commercially pure titanium grade 2 . The as-received titanium bar was heat-treated by the standard procedure $\left(650^{\circ} \mathrm{C}, 1\right.$ hour, air cooling). The microstructural evolution at moderate temperatures was investigated in situ by the X-ray diffraction (XRD) method. Low-temperature annealing was carried out in a heated chamber under vacuum (1-10-4 mbar) placed in a diffractometer. The temperatures of annealing were 300,400 and $500{ }^{\circ} \mathrm{C}$. XRD measurements were performed during annealing in time intervals of 15 minutes. The maximum time of annealing was 150 minutes for each temperature. The annealing temperature was increased gradually from 300 to $500{ }^{\circ} \mathrm{C}$. The XRD measurement were done in BraggBrentano geometry using a Co tube on anX'Pert PRO PANalytical diffractometer. The diffraction patterns were evaluated by the Rietveld-like TOPAS 3 program, which uses the so-called "fundamental parameter approach" [13], i.e. the calculated diffraction profile is based on convolution of the particular contribution to the diffraction profile. In order to determine the crystallite size and the microstrain more precisely, we used the Pawley fit, where the intensities are taken as free parameters.

\section{RESULTS AND DISCUSSION}

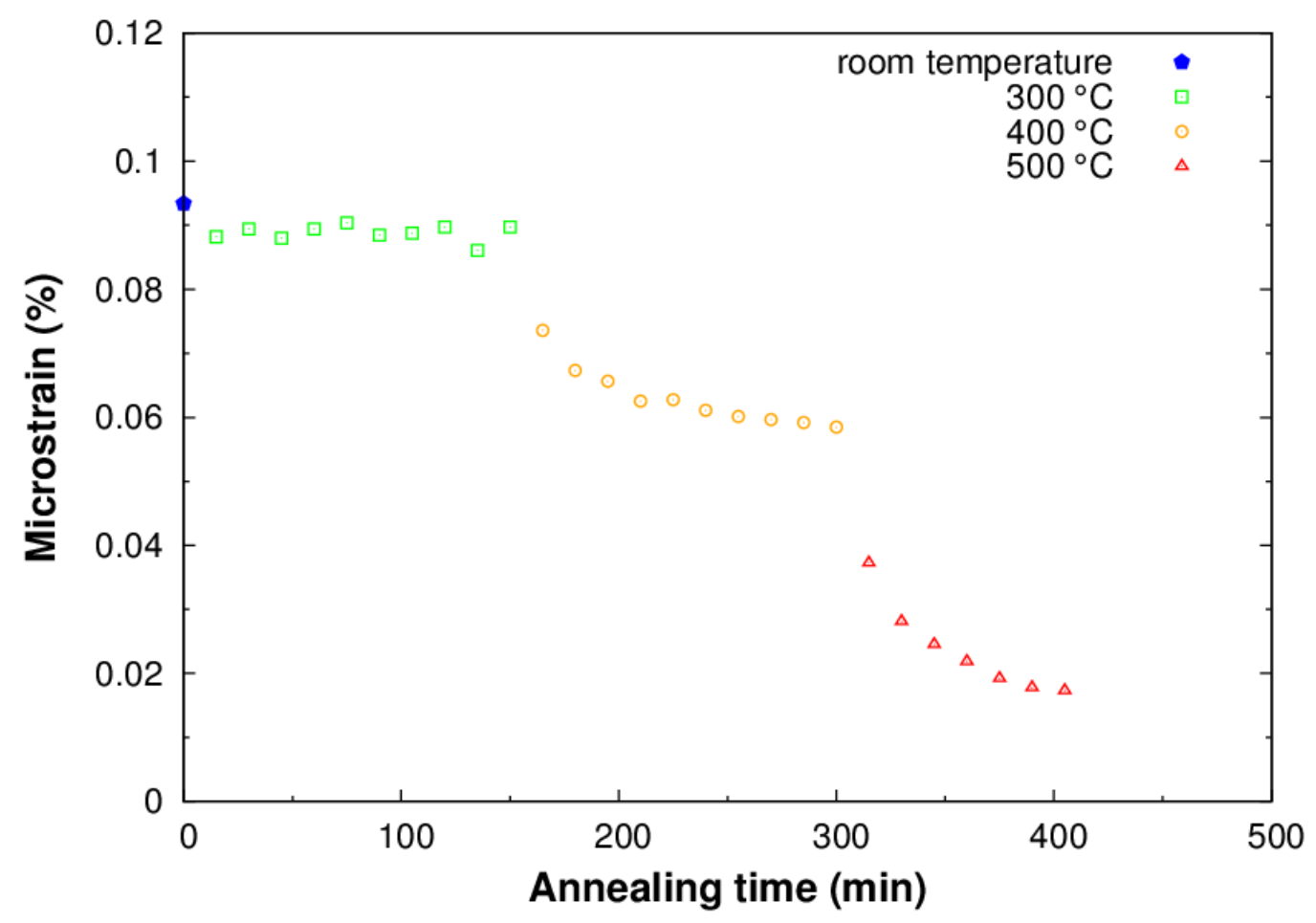

Figure 1 Evolution of microstrain during annealing with gradually increasing temperatures, measured by $\mathrm{XRD}$ at 15 -minute intervals 
Figure 1 presents the evolution of the microstrain with the gradually increasing annealing time (with a 15minute time interval between two measurements) and with gradually increasing temperature of 300,400 and $500^{\circ} \mathrm{C}$. A significant reduction in microstrain with increasing temperature of annealing is revealed. Microstrain of approximately 0.093 for the initial state was reduced to a value of approximately 0.087 for annealing at $300^{\circ} \mathrm{C}$, to a value of approximately 0.058 for annealing at $400{ }^{\circ} \mathrm{C}$, and to a value of approximately 0.017 for annealing at $500^{\circ} \mathrm{C}$. It can be seen that the microstrain drops rapidly in the initial stage of the annealing time for all temperatures. When a temperature of $300{ }^{\circ} \mathrm{C}$ is reached, the microstrain does not change with the annealing time. The macroscopic residual stress showed a similar course for temperatures from 200 to $500{ }^{\circ} \mathrm{C}$, as recently reported by Huang et al. [14]. However, the results presented here show that the microstrain is influenced by the annealing time at temperatures of 400 and $500^{\circ} \mathrm{C}$. A gradual decrease in microstrain from approximately 0.074 to approximately 0.058 with annealing time is evident during annealing at $400{ }^{\circ} \mathrm{C}$. There is an even more pronounced effect of annealing time at a temperature of $500^{\circ} \mathrm{C}$, when recrystallization occurs [4]. Here, a decrease in microstrain from approximately 0.037 to approximately 0.017 was registered. These results indicate a different trend of microstrain relaxation within the annealing temperatures in temperature range studied here.

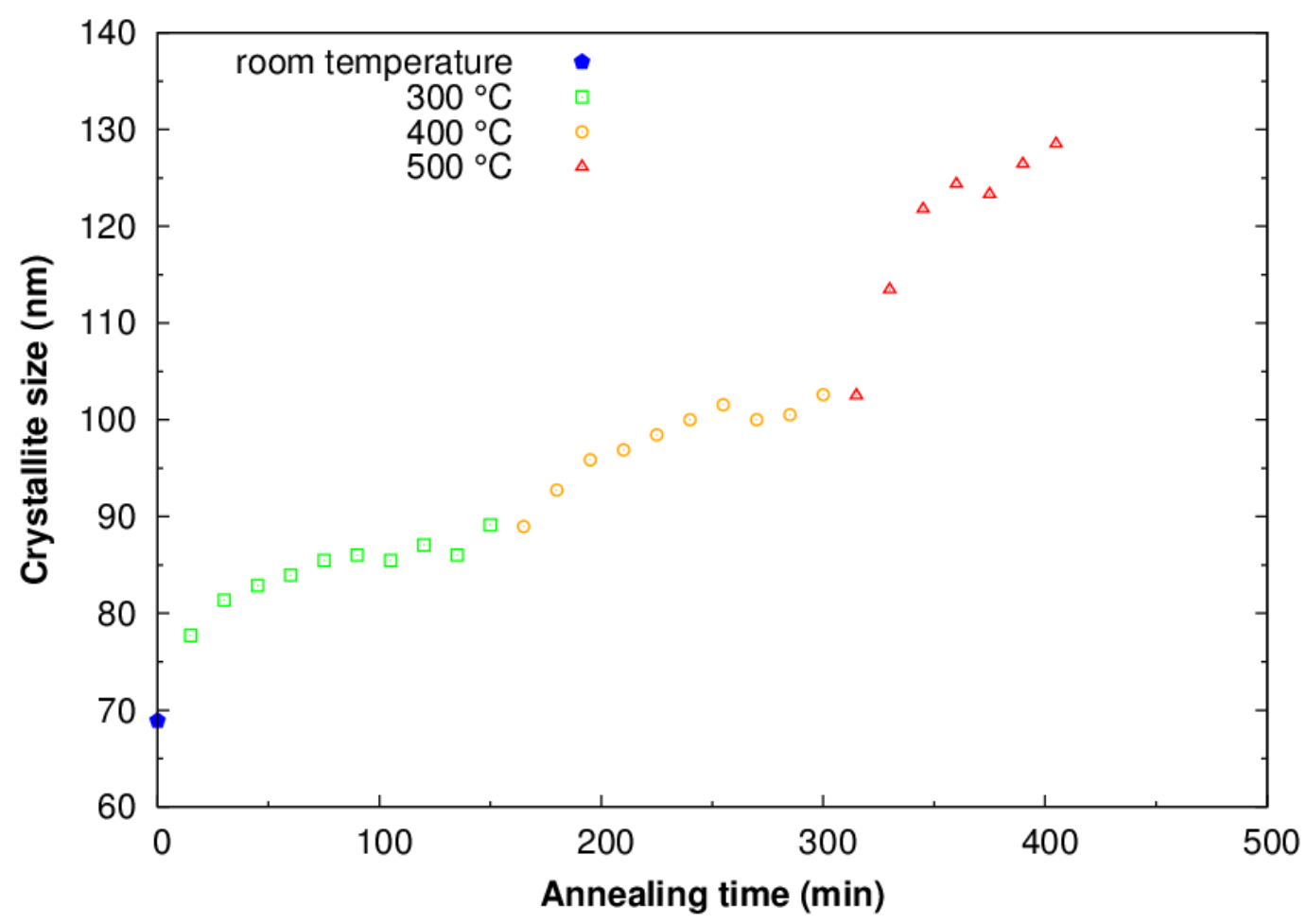

Figure 2 Crystallite size in dependence on the temperature and time of annealing, measured by XRD at 15 minute intervals

The gradual growth of crystallites with temperature and time of annealing is shown in Figure 2. The crystallite size increased from approximately $69 \mathrm{~nm}$ for the initial state to approximately $89 \mathrm{~nm}$ after annealing at $300^{\circ} \mathrm{C}$, to approximately $102 \mathrm{~nm}$ after annealing at $400{ }^{\circ} \mathrm{C}$, and to approximately $128 \mathrm{~nm}$ after annealing at $500{ }^{\circ} \mathrm{C}$. Unlike in the case of microstrain, crystallite growth with annealing time is observed already at a temperature of $300{ }^{\circ} \mathrm{C}$. The gradual growth of crystallite with annealing time was found to be from approximately 78 to approximately $89 \mathrm{~nm}$ for $300{ }^{\circ} \mathrm{C}$, from approximately 89 to approximately $102 \mathrm{~nm}$ for $400{ }^{\circ} \mathrm{C}$, and from approximately 102 to approximately $128 \mathrm{~nm}$ for $500^{\circ} \mathrm{C}$. The crystallite size increases almost linearly with the annealing time temperatures up to $500^{\circ} \mathrm{C}$. The slope of the linear dependence of crystallite growth is $0.065 \mathrm{~nm} \cdot \mathrm{s}^{-1}$ for $300{ }^{\circ} \mathrm{C}$ and $0.089 \mathrm{~nm} \cdot \mathrm{s}^{-1}$ for $400{ }^{\circ} \mathrm{C}$. The more intense increase in crystallite size at $500{ }^{\circ} \mathrm{C}$ 
indicates overall recrystallization of the structure, as reported by Liu et al. [6] and by Choi et al. [15]. The data for $500{ }^{\circ} \mathrm{C}$ annealing were fitted by a straight line with a significantly different slope $\left(0.258 \mathrm{~nm} \cdot \mathrm{s}^{-1}\right)$ in comparison with lower annealing temperatures. This indicates that the recrystallization process occurs in a greater extent.

\section{CONCLUSION}

The effect of moderate temperatures and time of annealing on the crystallite size and the microstrain of $\mathrm{CP} \mathrm{Ti}$ has been demonstrated. Significant microstrain relaxation with increasing temperature of annealing has been observed. Microstrain was reduced by $6.5,37.6$ and $81.7 \%$ after annealing at 300,400 and $500{ }^{\circ} \mathrm{C}$ for the maximum annealing time, respectively. Gradual growth of crystallites with a different trend was registered. The maximum increase in crystallite size was found to be 129,148 and $185 \%$ after annealing at 300,400 and $500{ }^{\circ} \mathrm{C}$ for the maximum annealing time, respectively. The time of annealing at a temperature of $300{ }^{\circ} \mathrm{C}$ affects the crystallite growth, but there is no microstrain relaxation. The results presented here show that temperatures well below the recrystallization limit also have an effect on crystallite growth and microstrain relaxation.

\section{ACKNOWLEDGEMENTS}

This research has been supported by Ministry of Education, Youth and Sports of the Czech Republic project SGS18/173/OHK2/3T/12 of the Czech Technical University in Prague and by AZV MZ CR project No. NV19-08-00070.

\section{REFERENCES}

[1] XU S.H., LIU Y., LIU B., WANG X. Microstructural evolution and mechanical properties of Ti-5Al-5Mo-5V-3Cr alloy by heat treatment with continuous temperature gradient, Transactions of Nonferrous Metals Society of China, Vol. 28, 2018, pp. 273-281.

[2] WANG K., WU M., YAN Z., LI D. Microstructure evolution and static recrystallization during hot rolling and annealing of an equiaxed-structure TC21 titanium alloy, Journal of Alloys and Compounds, 752 (2018) 14-22.

[3] SARMA J., KUMAR R., SAHOO A.K, PANDA A., Enhancement of material properties of titanium alloys through heat treatment process: A brief review, Materials Today: Proceedings, Article in Press.

[4] TERADA D., INOUE M., KITAHARA H., TSUJI N., Change in mechanical properties and microstructure of ARB processed Ti during annealing, Materials Transactions, Vol. 49, 2008, pp. 41-46.

[5] GUNDEROV D.V., POLYAKOV A.V., SITDIKOV V.D., CHURAKOVA A.A., GOLOVIN I.S. Internal friction and evolution of ultrafine-grained structure during annealing of Grade 4 titanium subjected to severe plastic deformation, Physics of Metals and Metallography, Vol. 114, 2013, pp. 1078-1085.

[6] LIU N., WANG Y., HE W., LI J., CHAPUDIS A., LUAN B., LIU Q. Microstructure and textural evolution during cold rolling and annealing of commercially pure titanium sheet, Transactions of Nonferrous Metals Society of China, Vol. 28, 2018, pp. 1123-1131.

[7] SOTNICZUK A., KUCZYŃSKA-ZEMŁA D., KROLIKOWSKI A., GARBACZ H. Enhancement of the corrosion resistance and mechanical properties of nanocrystalline titanium by low-temperature annealing, Corrosion Science, Vol.147, 2019, pp. 342-349

[8] HORAZDOVSKY T., VRBOVA R. Tribomechanical properties of a carbon-based nanolayer prepared by nitrogen ion beam assisted deposition for finger joint replacements, Journal of Nanomaterials, Vol. 2018, 2018, pp. 1-9, Art. No. 3749309.

[9] FOJT J., FILIP V., JOSKA L., On the increasing of adhesive strength of nanotube layers on beta titanium alloys for medical applications, Applied Surface science, Vol. 355, 2015, pp. 52-58.

[10] VLCAK P., DRAHOKOUPIL J., VERTAT P., SEPITKA J., DUCHON J. Hardness response to the stability of a $\mathrm{Ti}(+\mathrm{N})$ solid solution in an annealed $\mathrm{TiN} / \mathrm{Ti}(+\mathrm{N}) / \mathrm{Ti}$ mixture layer formed by nitrogen ion implantation into titanium. Journal of Alloys and Compounds, Vol. 746, 2018, pp. 490-495. 
[11] VLCAK P., FOJT J., WEISS Z., KOPECEK J, PERINA V. The effect of nitrogen saturation on the corrosion behaviour of Ti-35Nb-7Zr-5Ta beta titanium alloy nitrided by ion implantation, Surface and Coatings Technology, Vol. 358, 2019, pp. 144-152

[12] LIANG X., LIU Z., WANG B., State-of-the-art of surface integrity induced by tool wear effects in machining process of titanium and nickel alloys: A review, Measurement, Vol. 132, 2019, pp. 150-181.

[13] CHEARY R.W., COELHO A.A., CLINE J.P., Fundamental Parameters Line Profile Fitting in Laboratory Diffractometers, Journal of Research of the National Institute of Standards and Technology, Vol. 109, (2004, pp. 1-25.

[14] J. HUANG J., ZHANG K-M., JIA Y-F., et al. Effect of thermal annealing on the microstructure, mechanical properties and residual stress relaxation of pure titanium after deep rolling treatment, Journal of Materials Science \& Technology, Vol. 35, 2019, pp. 409-417.

[15] CHOI S-W., LI CH-L., WON J. W., et al. Deformation heterogeneity and its effect on recrystallization behavior in commercially pure titanium: Comparative study on initial microstructures, Materials Science and Engineering $A$, Vol. 764, 2019, Art. No. 138211. 